\title{
Erratum to: Mindfulness in Daily Life: a Multidimensional Approach
}

\author{
Elisabeth S. Blanke $^{1}$ Annette Brose ${ }^{1,2}$
}

Published online: 3 August 2017

(C) Springer Science+Business Media, LLC 2017

\section{Erratum to: Mindfulness (2017) 8:737-750 https://doi.org/10.1007/s12671-016-0651-4}

The authors would like to note a mistake which occurred at an early preprocessing step when correcting for trends in the data for the original published paper (a slightly diverged value was obtained for the detrended scores for items 5, 6, and 7 of the MSMQ). The mistake does not change any scientific conclusions drawn in the paper. Nevertheless, some of the estimates reported in the paper change slightly. Please note that all changes are subsequent errors to the same mistake that occurred while preprocessing the data. We now present the corrected values together with the values as previously reported in the paper [in squared brackets] for comparison.

Results section:

- Average ICC: 0.30 [0.24]

- Fit of the model with four first-order factors and a superordinate mindfulness factor: $\chi^{2}$ index

The online version of the original article can be found at https://doi.org/ 10.1007/s12671-016-0651-4

Elisabeth S. Blanke

elisabeth.blanke@hu-berlin.de

1 Institut für Psychologie, Humboldt-Universität zu Berlin, Unter den Linden 6, 10099 Berlin, Germany

2 KU Leuven, Leuven, Belgium $\chi^{2}(101)=681.24, p<0.01$

$\left[\chi^{2}(101)=691.84, p<0.01\right]$

- Satorra-Bentler Scaled Chi-Square Difference:

$\chi^{2}(1)=0.44, n s$.

$\left[\chi^{2}(1)=0.35, n s.\right]$

- Fit of the model with three first-order factors and a superordinate mindfulness factor: $\chi^{2}$ index and CFI

$\chi^{2}(49)=144.96, p<0.01 ; \mathrm{CFI}=0.98$

$\left[\chi^{2}(49)=152.90, p<0.01 ; \mathrm{CFI}=0.97\right]$

- Fit of the model with one factor: $\chi^{2}$ index, CFI, and SRMR $_{\text {between }}$

$\chi^{2}(54)=1667.11, p<0.01 ; \mathrm{CFI}=0.57 ; \mathrm{SRMR}_{\text {between }}=0.17$

$\left[\chi^{2}(54)=1632.46, p<0.01 ; \mathrm{CFI}=0.59 ; \mathrm{SRMR}_{\text {between }}=0.25\right]$

Strengths and Limitations section:

- ICCs of the mindfulness facets were low in general [but not especially low for nonjudgmental acceptance as was reported in the originally published article].

In the following, please find the corrected versions of Figs. 1 and 2, as well as Table 1, Table 3. We present the corrected values in bold, with the values as previously reported in the paper in squared brackets for comparison. 


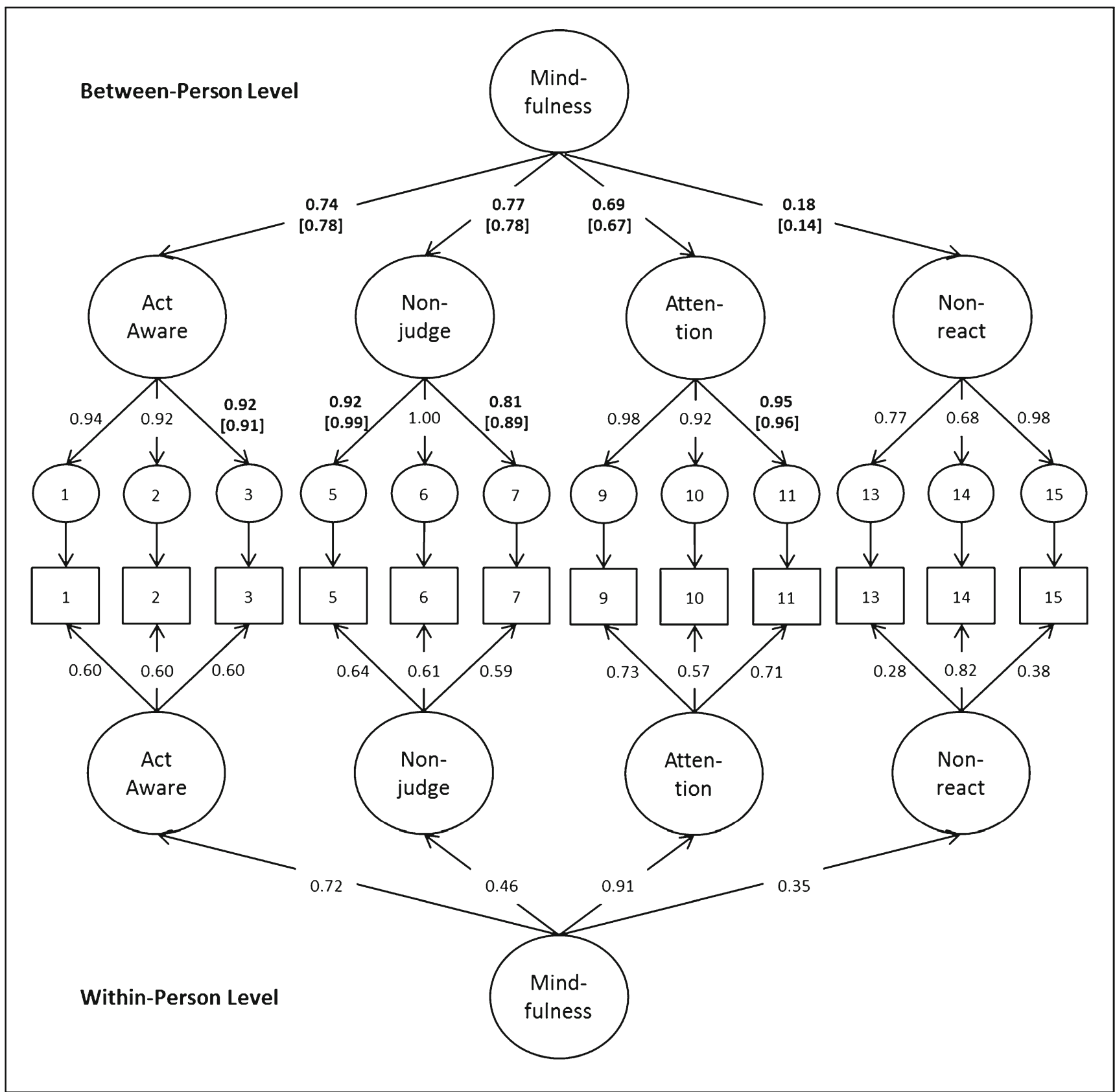

Fig. 1 Four-factor model with superordinate factors from multilevel confirmatory factor analysis (MCFA). Note. Standardized solution

Mplus. Variances are not displayed. Act aware acting with awareness, based on maximum-likelihood estimation with robust standard errors in Nonjudge nonjudgmental acceptance, Attention present-moment attention, Nonreact nonreactivity 
Fig. 2 Three-factor model with superordinate factors from multilevel confirmatory factor analysis (MCFA). Note.

Standardized solution based on maximum-likelihood estimation with robust standard errors in

Mplus. Variances are not displayed. Act aware acting with awareness, Nonjudge

nonjudgmental acceptance, Attention present-moment attention

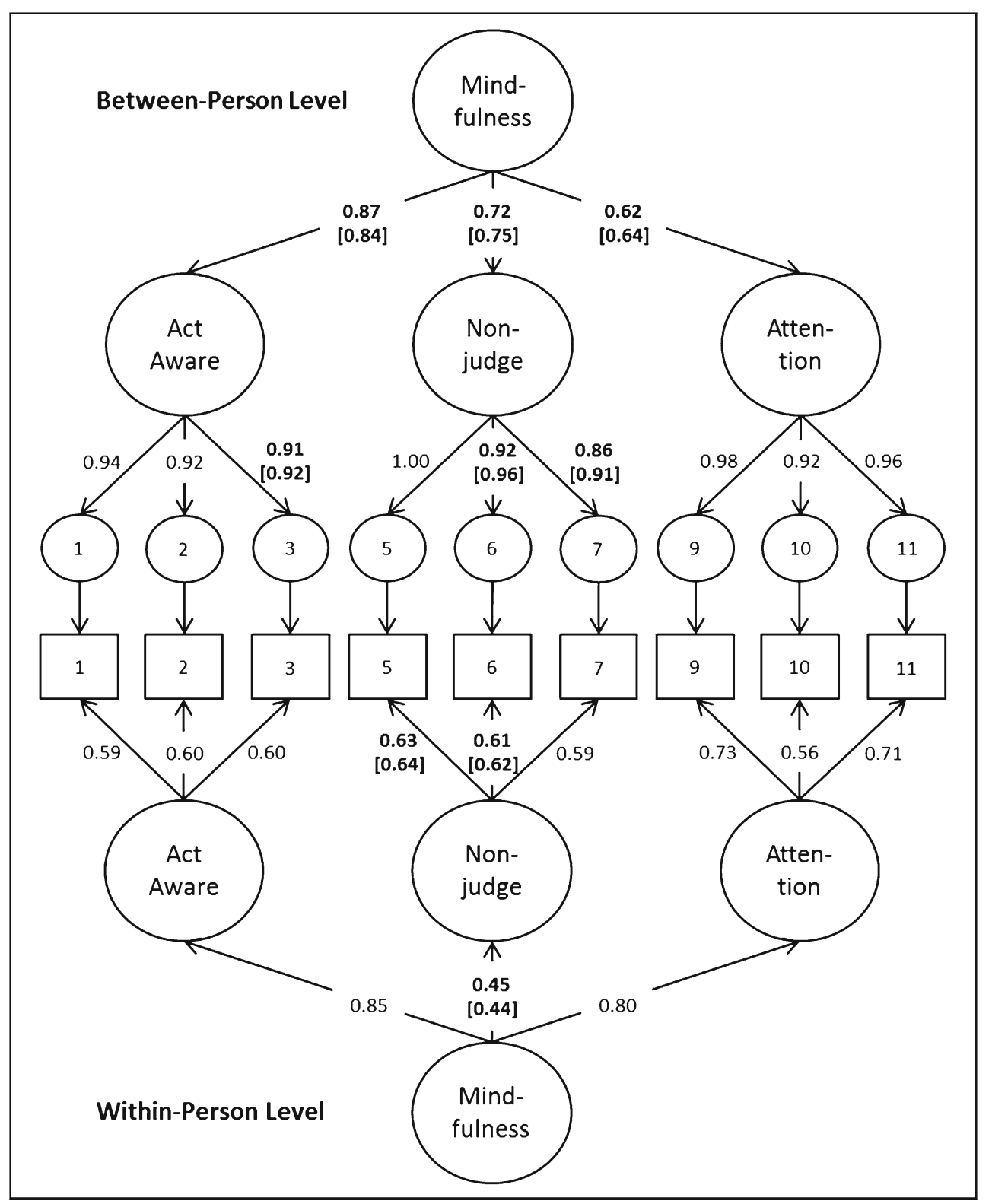


Table 1 Items of the Daily Mindfulness Questionnaire (MSMQ) with Descriptive Statistics $(N=70)$

MSMQ item description

No. Original item wording with source in italics and item number in parentheses
MSMQ items in English

[in original German]

In the period since the last

measurement/since I woke up, ...
Descriptive statistics

Null model SE ICC

estimate

Assumed facet: Acting with awareness

$1^{*} \quad$ I do jobs or tasks automatically without being aware of what I'm doing. MAAS (10)/FFMQ (34)

2* I find myself doing things without paying attention. MAAS (14)/FFMQ (38)

$3^{*} \quad$ I find it difficult to stay focused on what's happening in the present. MAAS (3)/ FFMQ(18)

4 I rush through activities without being really attentive to them. MAAS (8)/ FFMQ (28)

\section{Assumed facet: Nonjudgmental acceptance}

5* I believe some of my thoughts are abnormal or bad and I shouldn't think that way. FFMQ (14)/ KIMS (16); I think some of my emotions are bad or inappropriate and I shouldn't feel them. FFMQ (30)/ KIMS (32)

$6^{*} \quad$ I believe some of my thoughts are abnormal or bad and I shouldn't think that way. FFMQ (14)/ KIMS (16)

$7^{*}$

8 When I have distressing thoughts or images, I judge myself as good or bad, depending on what the thought/image is about. FFMQ (35)/ $M Q$ (8)

Assumed facet: Present-moment attention

9* I am able to focus on the present moment. CAMS-R (11)

$10^{*} \quad$ It is easy for me to concentrate on what I am doing. CAMS-R (1); I am able to focus on the present moment. CAMS-R (11)

$11 * \quad$ It is easy for me to concentrate on what I am doing. CAMS-R (1)
I did tasks/things automatically without being aware of what I'm doing. (R) [Ich habe Aufgaben/Dinge automatisch erledigt, ohne wirklich mitzubekommen, was ich tue. (R)]

I did things without paying attention. (R) [Ich habe Dinge getan, ohne auf sie zu achten. (R)]

I sometimes did not stay focused on what was happening in the present. (R) [Ich habe manchmal nicht auf das geachtet, was im jeweiligen Moment passiert ist. (R)]

I rushed through activities without being really attentive to them. (R) [Ich habe mich durch Aktivitäten gehetzt, ohne wirklich aufmerksam für sie zu sein. (R)]

I thought some of my thoughts/feelings were slightly off. (R) [Ich habe gedacht, dass manche meiner Gedanken/Gefühle etwas unpassend waren. (R)]

Things went through my mind that I should not really be engaging myself with. (R) [Mir sind Dinge durch den Kopf gegangen, die mich eigentlich nicht beschäftigen sollten. (R)]

I thought I could have acted more appropriately at a certain time. (R) [Ich habe gedacht, dass ich mich in einem bestimmten Moment hätte besser verhalten können. (R)]

I judged the things that were running through my head.(R)

[Ich habe das, was mir durch den Kopf ging, bewertet.(R)]

I focused my attention on the present Aufmerksamkeit auf den jeweils aktuellen Moment gerichtet.]

I opened myself up to what was happening. was gerade geschah.]

I concentrated on what I was doing at that moment. $\quad 3.85$ 
Table 1 (continued)

MSMQ item description

$\begin{array}{ll}\text { No. } & \text { Original item wording with } \\ \text { source in italics and item } \\ \text { number in parentheses }\end{array}$

12 It's easy for me to keep track of my thoughts and feelings. CAMS-R (8)

Assumed facet: Nonreactivity

$13^{*}$ I notice that I don't need to react to whatever pops into my mind. FMI (10)

14* I easily get lost in my thoughts and feelings. FFMQ (9); I watch my feelings without getting lost in them. FMI (25)

15* I accept unpleasant experiences. FMI (22)
MSMQ items in English

[in original German]

In the period since the last measurement/since I woke up, ...
Descriptive statistics

$\begin{aligned} & \text { Null model } \\ & \text { estimate }\end{aligned}$
SE $\quad$ ICC

I took note of my thoughts and feelings. [ Ich habe meine Gedanken und Gefühle wahrgenommen.]
I did not immediately react to the thoughts/feelings that popped into my head. [Ich habe auf die Gedanken/Gefühle, die mir in den Sinn kamen, nicht unmittelbar reagiert.]

I did not get engrossed in my thoughts/feelings. [Meine Gedanken/Gefühle haben mich nicht vereinnahmt.]

I accepted my thoughts/feelings without dwelling on them. [Ich habe meine Gedanken/Gefühle so hingenommen wie sie waren, ohne ihnen weiter nachzugehen.]
3.57

3.30

0.12

0.32

3.77

Note. Zero model estimates, standard errors (SE), and intraclass correlations (ICC) are based on the time-detrended data. Zero model estimates were calculated using SAS PROC MIXED. R = reverse-scored. ICCs are only shown for the items included in the confirmatory factor analyses; MAAS = Mindful Attention Awareness Scale (Brown \& Ryan, 2003); KIMS = Kentucky Inventory of Mindfulness (Baer et al., 2004); FFMQ = Five Facet Mindfulness Questionnaire (Baer et al., 2006); CAMS-R = Cognitive and Affective Mindfulness Scale Revised (Feldman et al., 2007); FMI = Freiburg Mindfulness Inventory (FMI; Buchheld et al., 2001; Walach et al., 2006); MQ = Mindfulness Questionnaire (MQ; Chadwick et al., 2005). Items marked with * were selected for the MSMQ

Table 3 Intercorrelations of the Latent MSMQ Factors (From Multilevel Confirmatory Factor Analysis (MCFA) Models Without a Superordinate Factor)

\begin{tabular}{|c|c|c|c|c|c|}
\hline \multicolumn{4}{|c|}{ Four-Factor Model } & \multicolumn{2}{|c|}{ Three-Factor Model } \\
\hline & Nonjudge & Attention & Nonreact & Nonjudge & Attention \\
\hline \multicolumn{6}{|c|}{ Between-person level } \\
\hline Act aware & $0.62 * *$ & $0.54 * *$ & -0.12 & $0.62 * *[0.63 * *]$ & $0.54 * *$ \\
\hline Nonjudge & & $0.44 * *[0.48 * *]$ & $0.21[0.24 \dagger]$ & & $0.44 * *[0.48 * *]$ \\
\hline Attention & & & 0.20 & & \\
\hline \multicolumn{6}{|c|}{ Within-person level } \\
\hline Act aware & $0.38^{* *}$ & $0.68 * *$ & 0.02 & $0.38 * *$ & $0.68 * *$ \\
\hline Nonjudge & & $0.36^{* *}\left[0.35^{* *}\right]$ & $0.48 * *[0.47 * *]$ & & $0.36 * *[0.35 * *]$ \\
\hline Attention & & & $0.36^{* *}$ & & \\
\hline
\end{tabular}

Note. Act aware = Acting with awareness, Nonjudge $=$ Nonjudgmental acceptance, Attention $=$ Present-moment attention; Nonreact $=$ Nonreactivity

$* * p<.01 . * p<.05 . \dagger p<.10$ 